\title{
Long-term Oncologic Outcomes of Robotic-assisted Radical Prostatectomy by a Single Surgeon
}

\author{
SHENG-CHUN HUNG ${ }^{1}$, CHEN-KUANG YANG $^{1}$, CHEN-LI CHENG $^{1}$ and YEN-CHUAN OU ${ }^{1,2}$ \\ ${ }^{1}$ Division of Urology, Department of Surgery and ${ }^{2}$ Department of Research, \\ Taichung Veterans General Hospital, Taichung, Taiwan, R.O.C.
}

\begin{abstract}
Aim: The aim of the study was to evaluate the longterm oncology outcomes of prostate cancer patients receiving robotic-assisted radical prostatectomy (RARP). Patients and Methods: We retrospectively evaluated 111 patients with clinically-localized prostate cancer receiving RARP with a mean follow-up of 103.43 months. Results: The 5-year BCRFS and 8year BCRFS among low-, intermediate-, and high-risk patients were $95.5 \%$ vs. $77.1 \%$ vs. $53.7 \%$ and $95.5 \%$ vs. $61.2 \%$ vs. $48.1 \%$ $(p=0.000)$. The median time to BCR in these three groups was 122.5, 98.0, and 79.2 months. Regarding postoperative factors, positive lymph node (HR=3.748, 95\% CI=1.407-9.984), pathology Gleason score ( $H R=1.507,95 \% C I=1.010-2.248)$, and postoperative nadir PSA $<0.003 \mathrm{ng} / \mathrm{ml}$ (HR=0.058, 95\% CI=0.020-0.166) were independent risk factors for BCR. Conclusion: D'Amico risk classification was effective at predicting biochemical recurrence in patients receiving RARP. Furthermore, postoperative risk factors such as metastatic lymph node, pathology Gleason score, and nadir PSA $<0.003 \mathrm{ng} / \mathrm{ml}$ were independent predictors of biochemical recurrence.
\end{abstract}

Since its introduction in 2000 , robotic-assisted radical prostatectomy (RARP), has become the standard treatment for clinically-localized prostate cancer (1). After the innovation and revolution of surgical technique and anatomical plain in the past decade, excellent trifecta outcome (undetectable PSA, urinary continence, and potency) and pentafecta outcome (trifecta outcome plus postoperative complications and negative surgical margins) have been

This article is freely accessible online.

Correspondence to: Yen-Chuan Ou, Division of Urology, Department of Surgery, Taichung Veterans General Hospital, Department of Research, Taichung Veterans General Hospital No. 1650, Sec. 4, Taiwan Boulevard, Taichung 40705, Taiwan, R.O.C. Tel: +886 423741215, Fax: +886 423593160, e-mail: ycou228@gmail.com

Key Words: Biochemical recurrence, long term follow-up, prostate cancer, robotic prostatectomy. reported and extensively examined world widely $(2,3)$. In our Institute, a high-volume center for prostate cancer and RARP in Taiwan, has succeeded more than 1,300 RARP and achieved an excellent functional and oncological outcome (4).

As RARP is still a relatively new procedure, the current literature mainly discusses oncology results in terms of biochemical failure (BCR) while long-term survival outcomes are less investigated. As we know, the characteristic of prostate cancer is slow growth and cancer-related death is not common (5). Thus, a short follow-up period may be insufficient to reveal the oncologic behavior and ten years survey may be required to discussing cancer-specific death. Studies discussing longterm oncology results have been reported and were mostly obtained from open or laparoscopic procedures, as a ten-year cohort reported results from laparoscopic radical prostatectomy with a 10-year biochemical failure-free survival rate that ranged from 78.1-97.2\% and a cancer-specific survival rate between $90.6-100 \%$, depending on the tumor stage (6). Currently, there is only one study discussing RARP with at least 10 years follow-up presenting the actuarial biochemicalfree survival, metastasis-free survival, and cancer-specific survival rates that were $73.1 \%, 97.5 \%$, and $98.8 \%$, respectively, and this is what we aimed to examine (7).

In this study, patients received RARP performed by a single surgeon at our medical center and the long-term oncology outcomes and survival benefit is herein discussed. Preoperative and postoperative risk factors specifically associated with the outcomes were also investigated.

\section{Patients and Methods}

We retrospectively evaluated 111 patients with clinically localized prostate cancer receiving RARP performed by a single surgeon at the Taichung Veterans General Hospital from December 2005 to December 2008. We performed RARP with a four-armed transperitoneal approach, as previously described $(8,9)$. In brief, after mobilization of seminal vesicles posteriorly, anterior approach retropubic radical prostatectomy would be performed $(10,11)$. The neurovascular bundle may be preserved depending on clinical staging and MRI (Magnetic Resonance Imaging). Limited pelvic lymph node dissection at the obturator fossa was done in most of 
the cases, while for patients with high risk or evidence of metastasis lymph node on imaging studies, extended pelvic lymph node dissection would be done (12).

Clinical stage was recorded using the staging system of the 2002 AJCC classification. Patients' characteristics and parameters were recorded including age, BMI (body mass index, $\mathrm{kg} / \mathrm{m}^{2}$ ), ASA score, prostate volume, biopsy Gleason score, biopsy positive chip amount, and biopsy tumor amount (\%). Preoperative risk was determined using the D'Amico classification (13).

Perioperative parameters were also recorded in Table I. After operation, specimens were examined using whole mounted prostate section. Pathology staging (pT2, pT3 and pT4), metastatic lymph node, pathology Gleason score, perineural invasion (PNI), angiolymphatic invasion (ALI), extracapsular extension (ECE), seminal vesical invasion (SVI), bladder neck invasion (BNI), surgical margin (SM), and tumor amount in specimen (\%) were also determined. A postoperative PSA below $0.003 \mathrm{ng} / \mathrm{mL}$ (measured using the PSA-RIACT kit, CisBio, France) during the follow-up period was defined as undetectable nadir PSA.

After operation, PSA would be checked at the first month, three monthly for at least two years, then six-month intervals thereafter. BCR was defined comprehensively following the guidelines of the American Urological Association as a serum PSA $>0.2 \mathrm{ng} / \mathrm{ml}$ with a subsequent confirmatory value (14).

Kaplan-Meier survival curve estimates and log-rank tests were used to test the association of biochemical-free survival (BCRFS), cancer-specific survival (CSS), and overall survival (OS) among the three groups according to the D'Amico risk classification. The univariate and multivariate analysis with the Cox proportional hazards model were used to predict the risk factors of BCRFS, CSS, and OS. Variables with $p$-values $<0.1$ in the univariate analysis or with a significant correlation to the result were checked in the multivariate model and $p<0.05$ was considered statistically significant.

Preoperative risk factors and postoperative risk factors of BCR were examined in a separate model. In Table II, two models were established to analyze the preoperative predictors of BCR. In the first model, we assessed the variables of preoperative risk factors and in the second model, we further examined the D'Amico risk classification.

In the model shown in Table III, we further examined the perioperative variables and pathology factors related to BCR. After analysis, the postoperative risk groups were determined by combining the levels of the independent predictors from the multivariable Cox model, which was further examined as in the second model in Table III.

All statistical tests were carried out using IBM SPSS version 22 for Windows (SPSS, Chicago, IL, USA).

\section{Results}

A total of 111 patients with a follow-up duration of at least 8 years (mean $=103.43 \pm 14.67$ months, median 107 months) were included in the study. Table I summarizes the characteristics of all patients by D'Amico risk stratification and there were 22 patients with low risk, 35 patients with intermediate risk, and 54 patients with high risk. A total of 3 patients died from malignancy and 2 patients died from non-cancerous cause (pneumonia and lymphoma). More positive biopsy chips and greater positive tumor amount were observed in the high-risk group, which may reflect the disease severity.

More pelvic lymph node dissection in the high-risk group with less neurovascular bundle preservation was noted, but no difference in estimated blood loss among the three groups $(p=0.516)$.

Pathology tumor staging revealed some degree of tumor up-staging while 4 pT3 (18.2\%) in the low-risk group; 21 $(60.0 \%)$ pT3 patients in the intermediate-risk group; 38 (70.4\%) pT3 patients and $2(3.7 \%)$ pT4 patients in the highrisk group $(p=0.000)$. A total of 10 patients $(9.0 \%)$ had metastatic lymph node, 1 within intermediate risk and 9 within high risk $(p=0.000)$. Patholgy Gleason score also appeared to be higher in the high-risk group $(p=0.000)$ and the incidence of risk factors such as PNI and ALI supported this result. ECE was more significant in high-risk group, while the incidence among the three group were $90.7 \%$, $77.1 \%$ and $45.5 \%(p=0.000)$. Positive SM among the three group were $61.1 \%, 51.4 \%$ and $18.2 \%$ and appear a significant problem in high risk group $(p=0.003)$.

Preoperative risk factors were examined in Table II. In the first model, PSA at diagnosis $(\mathrm{HR}=1.026,95 \% \mathrm{CI}=1.008$ $1.044)$, biopsy Gleason score $(\mathrm{HR}=1.563,95 \% \mathrm{CI}=1.09$ $2.223)$, and clinical $\mathrm{T}$ stage $(\mathrm{HR}=2.891,95 \% \mathrm{CI}=1.316$ 6.350) were identified as independent risk factors for BCR. D'Amico risk stratification was further examined in the second model and proved to be effective and an independent predictor $(\mathrm{HR}=2.194,95 \% \mathrm{CI}=1.146-4.201)$.

BCRFS, CSS, and OS were examined than among D'Amico risk groups. Figure 1a shows the 5-year BCRFS and 8-year BCRFS among low-, intermediate-, and high-risk patients were $95.5 \%$ vs. $77.1 \%$ vs. $53.7 \%$ and $95.5 \%$ vs. $61.2 \% v s .48 .1 \%(p=0.000)$, respectively. Furthermore, the median time to BCR in these three groups was 122.5, 98.0, and 79.2 months, respectively. We also observed that 3 patients died from prostate cancer and 1 of them was in the intermediate-risk group and 2 of them were in the high-risk group, while 8-year CSS was $97.1 \%$ in the intermediate-risk group and $95.8 \%$ were in the high-risk group (Figure 1b). Considering overall survival, there is 1 patient in the lowrisk group, 1 patient in the intermediate-risk group, and 3 patients in the high-risk group, while the 8-year OS among the three groups were $95.5 \%, 97.1 \%$, and $95.8 \%$, respectively (Figure 1c).

Postoperative risk factors were further examined, as shown in Table III. In the first model, pathology N stage (HR=3.748, 95\% CI=1.407-9.984), pathology Gleason Score ( $\mathrm{HR}=1.507$, $95 \% \mathrm{CI}=1.010-2.248)$ and achieved postoperative nadir PSA $<0.003 \mathrm{ng} / \mathrm{ml}(\mathrm{HR}=0.058,95 \% \mathrm{CI}=0.020-0.166)$ were shown to be independent risk factors for BCR.

An additional scoring system to evaluate postoperative risk for BCR was designed with lymph node invasion, 
Table I. Patients characteristics among D'Amico risk stratification of low-, intermediate-, and high-risk patients.

\begin{tabular}{|c|c|c|c|c|c|c|c|c|c|}
\hline \multirow[b]{2}{*}{ Age (years) } & \multicolumn{2}{|c|}{ Low risk $(n=22)$} & \multicolumn{2}{|c|}{ Intermediate risk $(\mathrm{n}=35)$} & \multicolumn{2}{|c|}{ High risk $(\mathrm{n}=54)$} & \multicolumn{2}{|c|}{ All $(n=111)$} & \multirow{2}{*}{$\frac{p \text {-Value }}{0.035^{*}}$} \\
\hline & 61.68 & \pm 7.15 & 65.46 & \pm 6.68 & 66.22 & \pm 6.94 & 65.08 & \pm 7.05 & \\
\hline BMI $\left(\mathrm{kg} / \mathrm{m}^{2}\right)$ & 24.89 & \pm 2.84 & 24.72 & \pm 3.27 & 24.42 & \pm 2.67 & 24.61 & \pm 2.88 & 0.790 \\
\hline ASA score & 2.00 & \pm 0.69 & 1.97 & \pm 0.57 & 1.91 & \pm 0.53 & 1.95 & \pm 0.57 & 0.771 \\
\hline PSA at diagnosis (ng/dL) & 6.28 & \pm 1.71 & 9.88 & \pm 4.25 & 29.22 & \pm 23.31 & 18.58 & \pm 19.44 & $0.000 *$ \\
\hline Biopsy Gleason score & 5.95 & \pm 0.21 & 6.40 & \pm 0.60 & 7.30 & \pm 1.33 & 6.75 & \pm 1.13 & $0.000 *$ \\
\hline Clinical T stage & & & & & & & & & $0.000 *$ \\
\hline $\mathrm{cT} 1$ & 17 & $77.3 \%$ & 20 & $57.1 \%$ & 9 & $16.7 \%$ & 46 & $41.4 \%$ & \\
\hline $\mathrm{cT} 2$ & 5 & $22.7 \%$ & 15 & $42.9 \%$ & 37 & $68.5 \%$ & 57 & $51.4 \%$ & \\
\hline cT3 & 0 & $0.0 \%$ & 0 & $0.0 \%$ & 8 & $14.8 \%$ & 8 & $7.2 \%$ & \\
\hline Prostate volume before operation $(\mathrm{mL})$ & 37.01 & \pm 14.48 & 35.09 & \pm 14.29 & 36.73 & \pm 12.24 & 36.28 & \pm 13.26 & 0.821 \\
\hline Positive biopsy chips amount & 2.40 & \pm 1.60 & 3.06 & \pm 1.81 & 4.88 & \pm 2.91 & 3.75 & \pm 2.55 & $0.000 *$ \\
\hline Biopsy tumor amount $(\%)$ & 10.36 & \pm 8.75 & 13.41 & \pm 10.42 & 34.25 & \pm 22.37 & 22.94 & \pm 20.31 & $0.000 *$ \\
\hline Dorsal vein ligation & 17 & $77.3 \%$ & 25 & $71.4 \%$ & 40 & $74.1 \%$ & 82 & $73.9 \%$ & 0.886 \\
\hline Bilateral pelvic lymph node dissection & 15 & $68.2 \%$ & 29 & $82.9 \%$ & 49 & $90.7 \%$ & 93 & $83.8 \%$ & 0.053 \\
\hline Neurovascular bundle preservation & & & & & & & & & $0.001 *$ \\
\hline Non & 7 & $31.8 \%$ & 18 & $51.4 \%$ & 42 & $79.2 \%$ & 67 & $60.9 \%$ & \\
\hline Unilateral & 6 & $27.3 \%$ & 7 & $20.0 \%$ & 8 & $15.1 \%$ & 21 & $19.1 \%$ & \\
\hline Bilateral & 9 & $40.9 \%$ & 10 & $28.6 \%$ & 3 & $5.7 \%$ & 22 & $20.0 \%$ & \\
\hline Blood loss (ml) & 225.23 & \pm 187.21 & 188.71 & \pm 200.05 & 240.74 & \pm 221.69 & 221.26 & \pm 208.01 & 0.516 \\
\hline Specimen volume (ml) & 42.27 & \pm 20.44 & 43.46 & \pm 17.17 & 43.85 & \pm 19.97 & 43.41 & \pm 19.06 & 0.949 \\
\hline Pathology T stage & & & & & & & & & $0.000 *$ \\
\hline pT2 & 18 & $81.8 \%$ & 14 & $40.0 \%$ & 14 & $25.9 \%$ & 46 & $41.4 \%$ & \\
\hline pT3 & 4 & $18.2 \%$ & 21 & $60.0 \%$ & 38 & $70.4 \%$ & 63 & $56.8 \%$ & \\
\hline pT4 & 0 & $0.0 \%$ & 0 & $0.0 \%$ & 2 & $3.7 \%$ & 2 & $1.8 \%$ & \\
\hline Pathology N stage & & & & & & & & & $0.022 *$ \\
\hline No & 22 & $100.0 \%$ & 34 & $97.1 \%$ & 45 & $83.3 \%$ & 101 & $91.0 \%$ & \\
\hline N1 & 0 & $0.0 \%$ & 1 & $2.9 \%$ & 9 & $16.7 \%$ & 10 & $9.0 \%$ & \\
\hline Pathology Gleason Score & 6.41 & \pm 0.67 & 7.00 & \pm 1.03 & 7.56 & \pm 1.14 & 7.15 & \pm 1.12 & $0.000 *$ \\
\hline Perineural invasion & 6 & $27.3 \%$ & 20 & $57.1 \%$ & 41 & $75.9 \%$ & 67 & $60.4 \%$ & $0.000 *$ \\
\hline Angiolymphatic invasion & 0 & $0.0 \%$ & 3 & $8.6 \%$ & 13 & $24.1 \%$ & 16 & $14.4 \%$ & $0.013 *$ \\
\hline Extracapsular extension & 10 & $45.5 \%$ & 27 & $77.1 \%$ & 49 & $90.7 \%$ & 86 & $77.5 \%$ & $0.000 *$ \\
\hline Positive surgical margin & 4 & $18.2 \%$ & 18 & $51.4 \%$ & 33 & $61.1 \%$ & 55 & $49.5 \%$ & $0.003 *$ \\
\hline Seminal vesical invasion & 1 & $4.5 \%$ & 4 & $11.4 \%$ & 21 & $38.9 \%$ & 26 & $23.4 \%$ & $0.001 *$ \\
\hline Bladder neck invasion & 0 & $0.0 \%$ & 0 & $0.0 \%$ & 1 & $1.9 \%$ & 1 & $0.9 \%$ & 0.587 \\
\hline Tumor amount in specimen $(\%)$ & 10.77 & \pm 9.28 & 18.45 & \pm 14.09 & 39.42 & \pm 29.07 & 27.13 & \pm 25.23 & $0.000 *$ \\
\hline Clavien-Dindo Complication Classification & & & & & & & & & 0.417 \\
\hline I & 0 & $0.0 \%$ & 1 & $2.9 \%$ & 5 & $9.3 \%$ & 6 & $5.4 \%$ & \\
\hline II & 2 & $9.1 \%$ & 2 & $5.7 \%$ & 2 & $3.7 \%$ & 6 & $5.4 \%$ & \\
\hline III & 1 & $4.5 \%$ & 1 & $2.9 \%$ & 0 & $0.0 \%$ & 2 & $1.8 \%$ & \\
\hline Foley duration & 9.00 & \pm 3.35 & 9.09 & \pm 2.52 & 9.83 & \pm 2.73 & 9.43 & \pm 2.81 & 0.342 \\
\hline Post operative stay, days & 5.18 & \pm 3.16 & 4.60 & \pm 2.96 & 3.93 & \pm 2.14 & 4.39 & \pm 2.66 & 0.149 \\
\hline Postoperative nadir PSA $(<0.003 \mathrm{ng} / \mathrm{dL})$ & 20 & $90.9 \%$ & 24 & $68.6 \%$ & 24 & $44.4 \%$ & 68 & $61.3 \%$ & $0.000 *$ \\
\hline Biochemical recurrence & 1 & $4.5 \%$ & 12 & $34.3 \%$ & 28 & $51.9 \%$ & 41 & $36.9 \%$ & $0.001 *$ \\
\hline Cancer-specific death & 0 & $0.0 \%$ & 1 & $2.9 \%$ & 2 & $3.7 \%$ & 3 & $2.7 \%$ & 0.664 \\
\hline Overall death & 1 & $4.5 \%$ & 1 & $2.9 \%$ & 3 & $5.6 \%$ & 5 & $4.5 \%$ & 0.835 \\
\hline Follow-up months & 104.77 & \pm 15.05 & 104.09 & \pm 14.59 & 102.46 & \pm 14.78 & 103.43 & \pm 14.67 & 0.786 \\
\hline
\end{tabular}

One-way ANOVA test for continuous variables (mean \pm SD) and Pearson Chi Square test for categorized variables [number (\%)], statistical significance $p<0.05 *$. BMI, Body mass index; ASA, American Society of Anesthesiologists Physical Status classification.

postoperative undetectable nadir PSA and pathology Gleason score. Positive lymph node was scored as 1 and negative was scored as 0 . If patients achieved undetectable nadir PSA after operation, they would be scored 0 and failed to achieve undetectable PSA would be scored 1. Pathology Gleason score also scored in group, while $>7,=7$ and $<7$ would be scored as 2,1 and 0 . The sum of all these three factors were categorized using a scale from $0 \sim 4$ : low risk, 0 ; intermediate risk, 1 2; high risk, 3 4. This postoperative scoring system was further examined in the second model, shown in Table III, and appeared to be an independent predictor for BCR $(\mathrm{HR}=8.705,95 \% \mathrm{CI} 3.553-21.328)$. 
Table II. Univariate and multivariate Cox proportional hazard regression analysis, using preoperative risk factors for prediction of biochemical recurrence.

\begin{tabular}{|c|c|c|c|c|c|c|}
\hline \multirow[b]{2}{*}{ Covariate } & \multicolumn{2}{|c|}{ Univariate } & \multicolumn{2}{|c|}{ Multivariate } & \multicolumn{2}{|c|}{ Multivariate } \\
\hline & $\mathrm{HR}(95 \% \mathrm{CI})$ & $p$-Value & $\mathrm{HR}(95 \% \mathrm{CI})$ & $p$-Value & $\operatorname{HR}(95 \% \mathrm{CI})$ & $p$-Value \\
\hline Age & $1.041(0.94-1.090)$ & 0.091 & $1.014(0.958-1.074)$ & 0.63 & $1.014(0.959-1.072)$ & 0.616 \\
\hline BMI & $0.949(0.848-1.062)$ & 0.366 & & & & \\
\hline ASA & $1.009(0.590-1.723)$ & 0.975 & & & & \\
\hline D'Amico Risk & $2.534(1.509-4.255)$ & 0.000 & & & $2.194(1.146-4.201)$ & $0.018 *$ \\
\hline PSA at diagnosis & $1.026(1.015-1.037)$ & 0.000 & $1.026(1.008-1.044)$ & $0.005^{*}$ & & \\
\hline Prostate volume before operation & $0.987(0.962-1.012)$ & 0.290 & & & & \\
\hline Biopsy Gleason Score & $1.864(1.442-2.409)$ & 0.000 & $1.563(1.09-2.223)$ & $0.013 *$ & & \\
\hline Positive biopsy chips amount & $1.240(1.105-1.390)$ & 0.000 & $1.127(0.905-1.402)$ & 0.285 & $1.190(0.991-1.430)$ & 0.062 \\
\hline Biopsy tumor amount $(\%)$ & $10.643(2.949-38.414)$ & 0.000 & $0.169(0.006-4.652)$ & 0.293 & $0.640(0.048-8.464)$ & 0.735 \\
\hline Clinical $\mathrm{T}$ stage & $4.027(2.275-7.126)$ & 0.000 & $2.891(1.316-6.350)$ & $0.008 *$ & & \\
\hline
\end{tabular}

BMI, Body mass index; ASA, American Society of Anesthesiologists Physical Status classification.

Table III. Univariate and multivariate Cox proportional hazard regression analysis, using postoperative risk factors for prediction of biochemical recurrence.

\begin{tabular}{|c|c|c|c|c|c|c|}
\hline & \multicolumn{2}{|c|}{ Univariate } & \multicolumn{2}{|c|}{ Multivariate } & \multicolumn{2}{|c|}{ Multivariate } \\
\hline & $\mathrm{HR}(95 \% \mathrm{CI})$ & $p$-Value & $\operatorname{HR}(95 \% \mathrm{CI})$ & $p$-Value & $\mathrm{HR}(95 \% \mathrm{CI})$ & $p$-Value \\
\hline Dorsal vein ligation & $1.496(0.690-3.245)$ & 0.308 & & & & \\
\hline Bilateral pelvic lymph node dissection & $1.631(0.639-4.161)$ & 0.306 & & & & \\
\hline Neurovascular bundle preservation & $0.562(0.349-0.905)$ & 0.018 & $0.795(0.444-1.422)$ & 0.439 & $0.635(0.370-1.091)$ & 0.100 \\
\hline Blood loss (ml) & $1.001(1.000-1.002)$ & 0.195 & $1.000(0.998-1.001)$ & 0.729 & $1.000(0.999-1.002)$ & 0.730 \\
\hline Specimen volume (ml) & $0.988(0.969-1.007)$ & 0.229 & & & & \\
\hline Pathology T stage & $4.426(2.036-9.619)$ & 0.000 & $0.503(0.116-2.175)$ & 0.358 & $0.998(0.239-4.166)$ & 0.998 \\
\hline Pathology N stage & $17.049(7.525-38.628)$ & 0.000 & $3.748(1.407-9.984)$ & $0.008^{*}$ & & \\
\hline Pathology Gleason Score & $1.924(1.476-2.509)$ & 0.000 & $1.507(1.010-2.248)$ & $0.044 *$ & & \\
\hline Perineural invasion & $4.253(1.882-9.609)$ & 0.001 & $1.181(0.357-3.905)$ & 0.785 & $2.424(0.790-7.436)$ & 0.122 \\
\hline Angiolymphatic invasion & $3.592(1.790-7.208)$ & 0.000 & $1.153(0.426-3.120)$ & 0.779 & $0.896(0.329-2.443)$ & 0.830 \\
\hline Tumor amount in specimen (\%) & $11.895(4.373-32.353)$ & 0.000 & $0.338(0.054-2.137)$ & 0.249 & $0.384(0.069-2.145)$ & 0.275 \\
\hline Extracapsular extension & $3.277(1.167-9.197)$ & 0.024 & $1.026(0.208-5.060)$ & 0.975 & $0.391(0.561-5.584)$ & 0.242 \\
\hline Surgical margin positive & $4.656(2.220-9.766)$ & 0.000 & $2.994(0.984-9.110)$ & 0.053 & $1.770(0.561-5.584)$ & 0.330 \\
\hline Seminal vesical invasion & $5.084(2.736-9.447)$ & 0.000 & $1.261(0.537-2.964)$ & 0.595 & $1.919(0.829-4.445)$ & 0.128 \\
\hline Bladder neck invasion & $13.327(1.667-106.557)$ & 0.015 & $5.224(0.227-120.073)$ & 0.301 & $7.722(0.452-131.866)$ & 0.158 \\
\hline Foley duration, days & $1.091(0.987-1.205)$ & 0.088 & $0.878(0.748-1.031)$ & 0.112 & $0.897(0.773-1.041)$ & 0.151 \\
\hline Postoperative stay, days & $1.016(0.910-1.134)$ & 0.775 & & & & \\
\hline Postoperative undetectable nadir PSA & $0.063(0.027-0.145)$ & 0.000 & $0.058(0.020-0.166)$ & $0.000^{*}$ & & \\
\hline Postoperative risk Score & $9.440(5.105-17.355)$ & 0.000 & & & $8.705(3.553-21.328)$ & $0.000 *$ \\
\hline
\end{tabular}

Post-operative risk score: low risk 0 , intermediate risk 1-2, high risk 3-4.

The efficacy of this postoperative risk score was examined for BCRFS, CSS, and OS. In Figure 2a, 5-year BCRFS, and 8 -year BCRFS were significantly poor in the high-risk group, while the rates among the low-, intermediate- and high-risk groups were $95.70 \%$ vs. $79.10 \%$ vs. $9.50 \%$ and $95.70 \%$ vs. $68.0 \%$ vs. $4.8 \%(p=0.000)$, respectively. The analysis for CSS is presented and all three patients who died from prostate cancer were in the high-risk group, while 8- year CSS rates in the low, intermediate and high-risk group were $100 \%, 100 \%$ and $90.5 \%$, respectively (Figure $2 b$ ). Similarly, it seemed that some difference existed in OS among the three groups and the 8-year OS among low-, intermediate- and high-risk groups were $100 \%, 96.5 \%$ and 90.5\%, respective (Figure 2c).

A total 41 patients that received salvage management were recorded and the risk group was discussed. All of them 

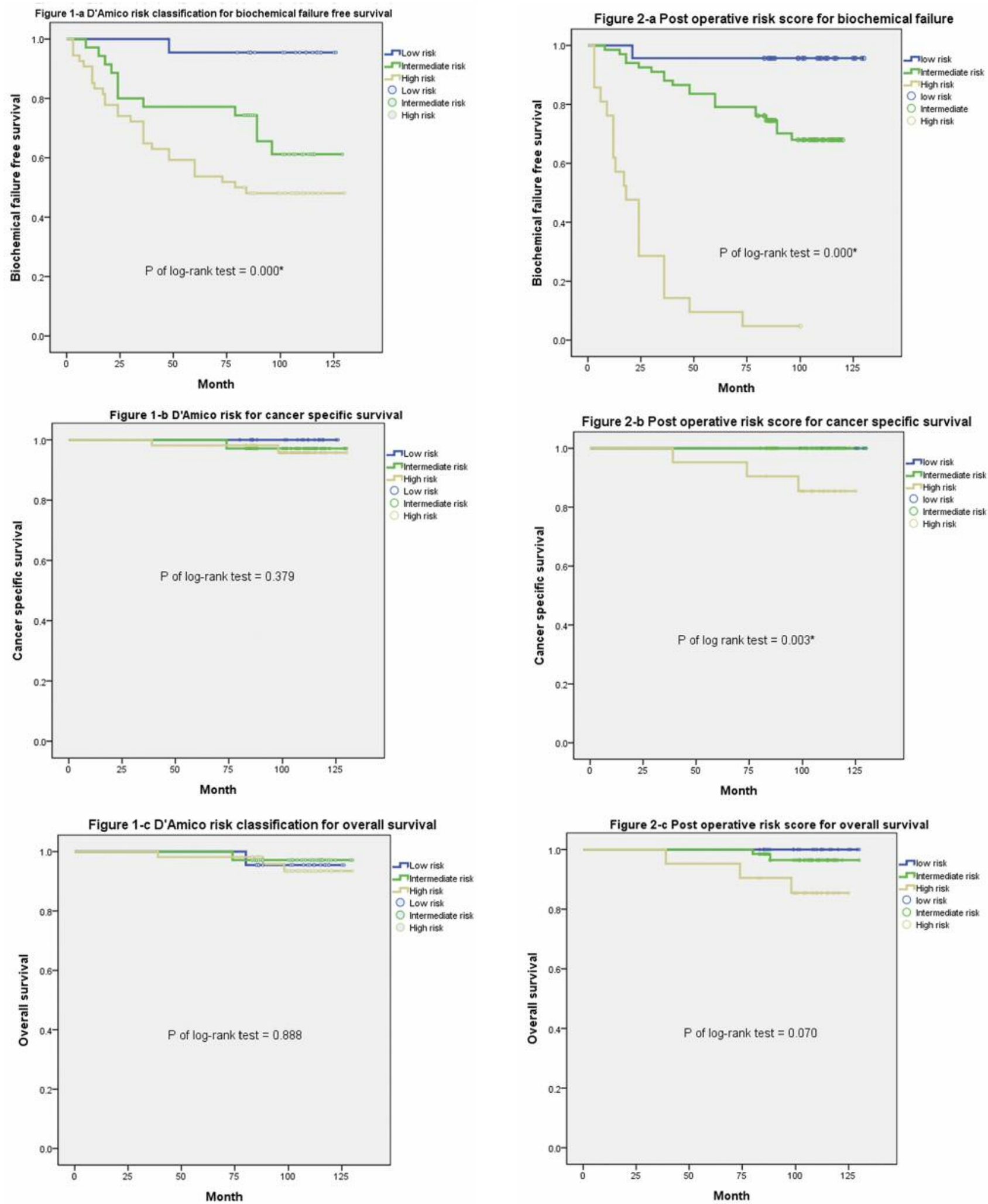

Figure 1. Kaplan-Meier survival curve for evaluation of disease progression by D'Amico risk classification: (a) biochemical recurrencefree survival, (b) cancer-specific survival, (c) overall survival.

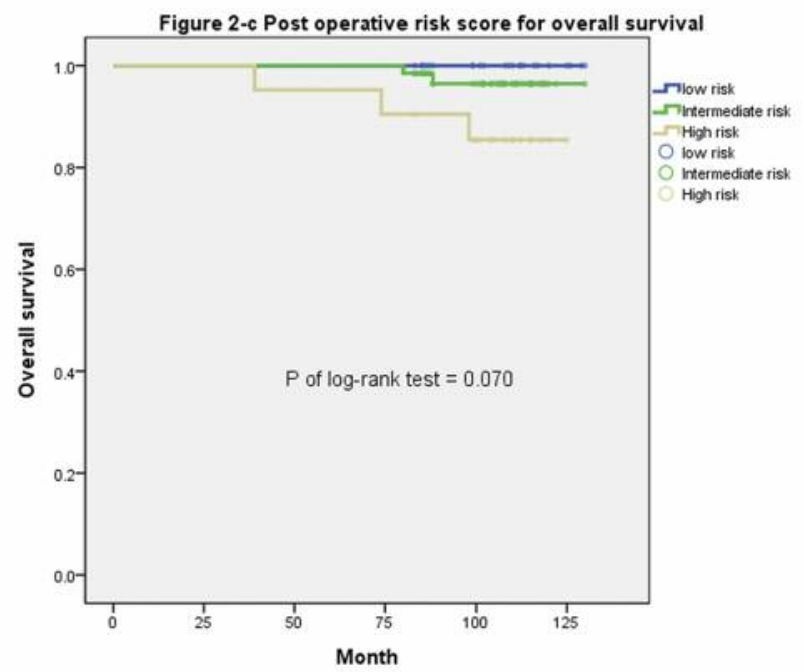

Figure 2. Kaplan-Meier survival curve for evaluation of disease progression by postoperative risk classification: (a) biochemical recurrence-free survival, (b) cancer-specific survival, (c) overall survival. 

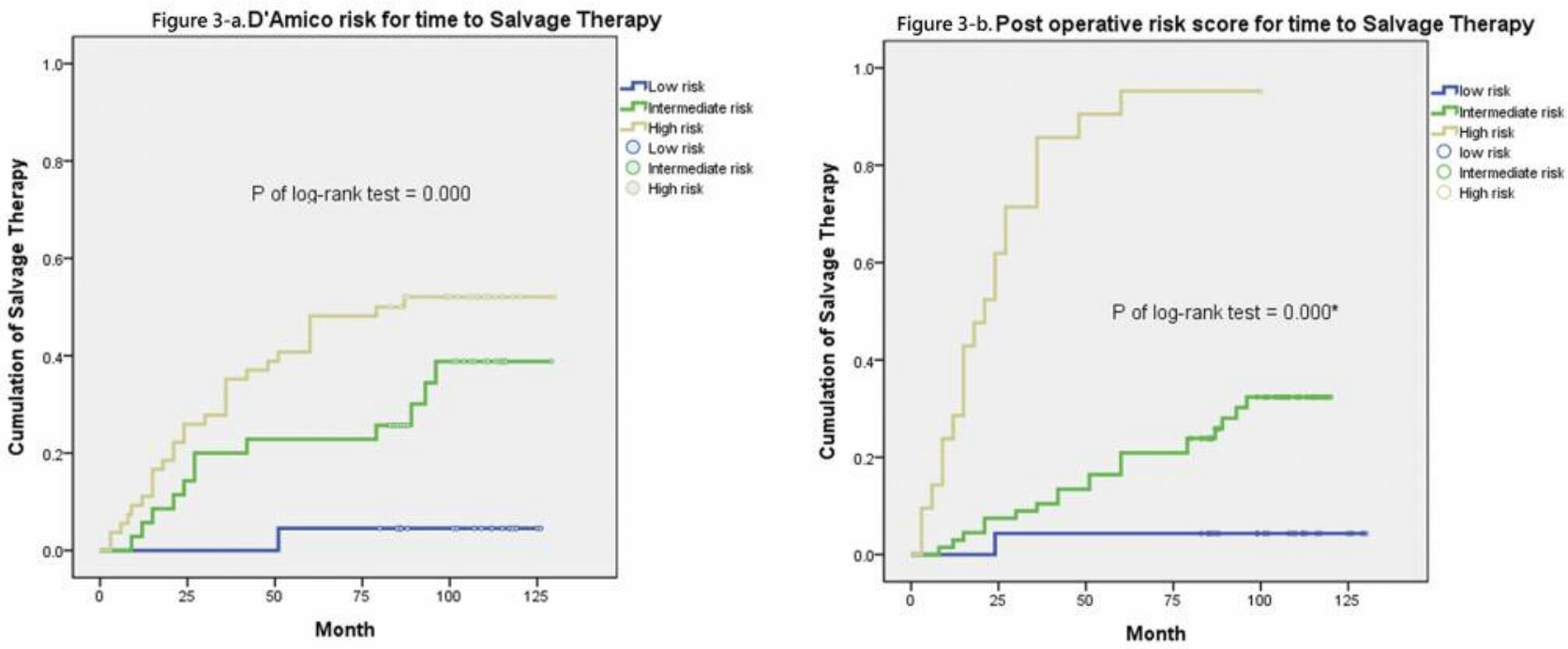

Figure 3. (a) Evaluation of patients who received salvage therapy in D'Amico classification with low, intermittent and high risk. It appears in patients with low risk preopertive category, the incidence of salvage therapy is relative low. The mean time to salvage therapy in low, intermittent and high risk group were $122.59 \pm 3.33,98.38 \pm 7.59$ and $79.49 \pm 6.98$ months. All of these three groups do not reach median time to therapy. The 2year salvage therapy and 5-year salvage therapy among low-, intermediate-, and high-risk patients were $4.5 \%$ vs. $14.3 \% \mathrm{vs.} 25.9 \%$ and $4.5 \% \mathrm{vs}$. $22.9 \% \mathrm{vs} .48 .1 \%$ ( $p$ of log-rank test=0.010). (b) Evaluation of patients who received salvage therapy in post-operative risk classification with low, intermittent and high risk. Most of the patients in the high risk group sufferred from early biochemical failure and median time to failure was $21.00 \pm 5.15$ month. Both low and intermediate risk do not reach the median time to therapy. The mean time to salvage therapy in low, intermittent and high risk group were $125.39 \pm 4.51,98.87 \pm 4.29$ and $25.91 \pm 4.79$ months. The 2-year salvage therapy and 5-year salvage therapy among low-, intermediate-, and high-risk patients were $4.3 \%$ vs. $7.5 \%$ vs. $61.9 \%$ and $4.3 \%$ vs. $20.9 \%$ vs. $95.2 \%$ ( $p$ of log-rank test $=0.000$ ).

received androgen-deprivation therapy and 10 of them received salvage radiation therapy. The mean time to salvage therapy in low-, intermittent- and high-risk group were $122.59 \pm 3.33, \quad 98.38 \pm 7.59$ and $79.49 \pm 6.98$ month, respectively (Figure $3 \mathrm{a}$ and $\mathrm{b}$ ).

\section{Discussion}

Few studies have investigated the long-term oncological results in patients who have received RARP and most are metaanalyses or review articles. In contrast, in our study, we conducted a long-term follow-up of patients treated by a single surgeon in the same Institute, which thereby avoided the confounding effects of the learning curve, as well as differences in surgical technique and skill among different surgeons.

In the era of open radical prostatectomy, Lue et al. reported a large series of 5,845 patients with at least ten years' follow-up that was found to confer a greater all caused survival benefit compared to watchful waiting (15). Furthermore, a study on laparoscopic and robotic-assisted surgery conducted over ten years showed comparable oncologic and functional results among the three investigated techniques (16). Hruza et al. reported that 370 consecutive patients received laparoscopic radical prostatectomy with a 10 -year progression-free survival rate that ranged from
97.2\% to $78.1 \%$ and a CSS rate between $100 \%$ and $90.6 \%$ (6). The long-term oncology outcome of robotic radical prostatectomy with a median 5-year follow-up was comparable with our results, with a 5-year BCR of $86.6 \%$ and median time to BCR was 60.2 months (17).

In our results, the predictive efficacy of the D'Amico risk classification (clinical stage, PSA, Gleason score) for BCR was confirmed. Low preoperative risk is associated with a low incidence of progression while high risk is correlated with a more aggressive disease behavior (18). Although the incidence of BCR in high-risk patients seemed to be high, aggressive management could still achieve benefits of low complication and good continence rate (19).

Up-grading after operation is an unavoidable issue and as common in our patients group, while a $39.7 \%$ of reported incidence of upgrading after radical prostatectomy compared to biopsy score (20-21). That is, to ensure better counseling for optimal treatment planning, preoperative risk factors may be somewhat insufficient for clinicians to predict the disease progression. Additional predictors after operation may help to hint the clinician as to whether intensive follow-up is needed. Three major factors (Gleason score, pathology lymph node, and postoperative undetectable nadir PSA) seemed to be independent of other factors in our cohort. Gleason score was first introduced in 1966 by Dr. Donald F. Gleason and is 
widely used in daily practice and research (22). It reflects the behavior of histological grade of neoplasm and the value of predicting $\mathrm{BCR}$ has been demonstrated in numerous studies worldwide (22). A Gleason score of 8-10 indicates a poor prognosis with actuarial 15-year recurrence-free survival, CSS, and OS rates of about $20.7 \%, 57.4 \%$, and $45.4 \%$, respectively (23). This finding is consistent with our result that showed Gleason score was an independent risk factor for $\mathrm{BCR}(\mathrm{HR}=1.507,95 \% \mathrm{CI}=.010-2.248)$.

Prostate cancer with lymph node involvement indicates a poor prognosis with a five-year BCR rate of $54 \%$ and even a ten-year survival rate of only $29 \%$ (24). Our result of positive lymph node may further suggest the importance and value of pelvic lymph node dissection, despite there is still some report about complications such as lymphocele, thromboembolic events, ureteral injury and nerve injury in literature, all of them are seldom in our population (12). In our experience, "Partin nomogram" was a useful tool for determining whether to perform radical prostatectomy, based on various factors including complications and oncology benefit (25).

The result of PSA may be at an undetectable level within 4 to 6 weeks following surgery and apparent disease-free status (26). Currently, there are few studies in the literature on the relationships between undetectable PSA within months and BCR. In our opinion, if the patients gain undetectable nadir PSA after operation, the disease may be considered less aggressive and it is reasonable to expect good disease behavior and low incidence of BCR. However, some studies have shown that there may still be $2.3 \%$ of patients with local and systemic disease progression in this situation, although there were some differences in the definition of undetectable PSA (27). As noted above, we performed PSA follow-up at 3-month intervals for more aggressive disease, to detect the variation of PSA.

Interestingly, after combining these three factors into a scoring system and categorizing the scores as low-, intermediate-, and high-risk, the difference of BCRFS in each group could be further confirmed. If patients had positive lymph nodes, Gleason score 8-10, and had not reached nadir PSA of $<0.003$, the disease course would be poor, with a median time to BCR of 18 months. Furthermore, we observed a relatively high incidence of CSS in this high-risk group. However, due to the limited case number and follow-up duration, a large series is needed to confirm these findings. In summary, the postoperative risk classification may provide clinicians with more information about disease failure, cancer recurrence, and the need for early intervention.

While our results are promising, some issues still need to be addressed. Factors such as PNI, ALI, tumor amount in prostate, ECE, and positive SM have negative effects on oncologic control. Ciftci et al. recently reported the predictive value of bone metastasis in patients with PNI, with an estimated 11-fold increased incidence of bone metastasis (28).
ALI, which is identified in about $20 \%$ of prostate cancer cases, appears to be an independent risk factor for PSA recurrence and cancer death in 504 patients and a median follow-up of 44 months (29). Positive SM and ECE have been reported as independent predictors for disease progression in some clinical series (30). In our study, all of the above mentioned factors showed significance in the univariate analysis. However, in the multivariate analysis, the efficacy and significance were relatively low and this may be confounded by the significance of undetectable nadir PSA.

There were some limitations in this study. This investigation describes the early experience of a single institute in Taiwan. The follow-up duration and small case number may be another limitation to look the difference in cancer-specific survival. Untra-sensitive PSA defined in $0.003 \mathrm{ng} / \mathrm{ml}$ was not available in some institute made the risk factor "undetectable PSA" in limited used clinically.

In conclusion, the long-term follow-up of patients who received robotic-assisted laparoscopic radical prostatectomy, D'Amico risk classification was effective in predicting biochemical recurrence. Furthermore, postoperative factors such as metastatic lymph node, pathology Gleason score, and postoperative nadir PSA $<0.003 \mathrm{ng} / \mathrm{ml}$ appeared to be independent predictors of biochemical recurrence.

\section{Conflicts of Interest}

None of the contributing authors have any conflict of interests, including specific financial interests or relationships and affiliations relevant to the subject matter or materials discussed in the manuscript.

\section{Ethical Approval}

This study has the institute with human ethical issue and the institute review board number was CE15215B.

\section{References}

1 Menon M, Shrivastava A, Tewari A, Sarle R, Hemal A, Peabody JO and Vallancien G: Laparoscopic and robot assisted radical prostatectomy: establishment of a structured program and preliminary analysis of outcomes. J Urol 168(3): 945-949, 2002.

2 Patel VR, Coelho RF, Chauhan S, Orvieto MA, Palmer KJ, Rocco B, Sivaraman A and Coughlin G: Continence, potency and oncological outcomes after robotic-assisted radical prostatectomy: early trifecta results of a high-volume surgeon. BJU Int 106(5): 696-702, 2010.

3 Patel VR, Sivaraman A, Coelho RF, Chauhan S, Palmer KJ, Orvieto MA, Camacho I, Coughlin G and Rocco B: Pentafecta: a new concept for reporting outcomes of robot-assisted laparoscopic radical prostatectomy. Eur Urol 59(5): 702-707, 2011.

4 Ou YC, Yang CK, Kang HM, Chang KS, Wang J, Hung SW, Tung MC, Tewari AK and Patel VR: Pentafecta outcomes of 230 cases of robotic-assisted radical prostatectomy with bilateral neurovascular bundle preservation. Anticancer Res 35(9): 50075013,2015 
5 L. Klotz: Active surveillance for prostate cancer: patient selection and management. Curr Oncol 17(Suppl 2): S11-S17, 2010.

6 Hruza M, Bermejo JL, Flinspach B, Schulze M, Teber D, Rumpelt HJ and Rassweiler JJ: Long-term oncological outcome after laparoscopic radical prostatectomy. BJU Int 111(2): 271280, 2013.

7 Diaz M, Peabody JO, Kapoor V, Sammon J, Rogers CG, Stricker H, Lane Z, Gupta N, Bhandari M and Menon M: Oncologic outcomes at 10 years following robotic radical prostatectomy. Eur Urol 67(6): 1168-1176, 2015.

8 Ou YC, Yang CR, Wang J, Cheng CL and Patel VR: Roboticassisted laparoscopic radical prostatectomy: learning curve of first 100 cases. Int J Urol 17(7): 635-640, 2010.

9 Patel VR, Tully AS, Holmes R and Lindsay J: Robotic radical prostatectomy in the community setting - the learning curve and beyond: initial 200 cases. J Urol 174(1): 269-272, 2005.

10 Hung SC, Ou YC, Cheng CL, SW Hung, Ho HC, Chiu KY, Wang SS, Chen CS, L JR and Yang CK: Standardized procedure of robotic assisted laparoscopic radical prostatectomy from case 1 to case 1200. Urol Sci 27(4): 199-207, 2016.

11 Van Velthoven RF, Ahlering TE, Peltier A, Skarecky DW and Clayman RV: Technique for laparoscopic running urethrovesical anastomosis: the single knot method. Urology 61: 699-702, 2003.

12 Briganti A, Blute ML, Eastham JH, Graefen M, Heidenreich A, Karnes JR, Montorsi F and Studer UE: Pelvic lymph node dissection in prostate cancer. Eur Urol 55(6): 1251-1265, 2009.

13 D'Amico AV, Whittington R, Malkowicz SB, Schultz D, Blank K, Broderick GA, Tomaszewski JE, Renshaw AA, Kaplan I, Beard CJ and Wein A: Biochemical outcome after radical prostatectomy, external beam radiation therapy, or interstitial radiation therapy for clinically localized prostate cancer. JAMA 280(11): 969-974, 1998.

14 Cookson MS, Aus G, Burnett AL, Canby-Hagino ED, D'Amico AV, Dmochowski RR, Eton DT, Forman JD, Goldenberg SL, Hernandez J, Higano CS, Kraus SR, Moul JW, Tangen C, Thrasher JB and Thompson I: Variation in the definition of biochemical recurrence in patients treated for localized prostate cancer: the American Urological Association Prostate Guidelines for Localized Prostate Cancer Update Panel report and recommendations for a standard in the reporting of surgical outcomes. J Urol 177(2): 540-545, 2007.

15 Liu L, Coker AL, Du XL, Cormier JN, Ford CE and Fang S: Long-term survival after radical prostatectomy compared to other treatments in older men with local/regional prostate cancer. J Surg Oncol 97(7): 583-91, 2008.

16 Finkelstein J, Eckersberger E, Sadri H, Taneja SS, Lepor H and Djavan B: Open versus laparoscopic versus robot-assisted laparoscopic prostatectomy: the European and US experience. Rev Urol 12(1): 35-43, 2010.

17 Menon M, Bhandari M, Gupta N, Lane Z, Peabody JO and Rogers CG: Biochemical recurrence following robot-assisted radical prostatectomy: analysis of 1384 patients with a median 5-year follow-up. Eur Urol 58(6): 838-846, 2010.

18 Chang AJ, Autio KA, Roach M and Scheer HI: "High-Risk" Prostate cancer: classification and therapy. Nat Rev Clin Oncol 11(6): 308-323, 2014.
19 Yuh B, Artibani W, Heidenreich A, Kimm S, Menon M and Novara G: The role of robot-assisted radical prostatectomy and pelvic lymph node dissection in the management of high-risk prostate cancer: a systematic review. Eur Urol 65(5): 918-927, 2014.

20 D'Elia C, Cerruto MA, Cioffi A, Novella G, Cavalleri S and Artibani W: Upgrading and upstaging in prostate cancer: From prostate biopsy to radical prostatectomy. Mol Clin Oncol 2(6): 1145-1149, 2014.

$21 \mathrm{Ou}$ YC, Yang CK, Chang KS, Wang J, Hung SW, Tung MC, Tewari AK and Patel VR: Prevention and management of complications during robotic-assisted laparoscopic radical prostatectomy following comprehensive planning: a large series involving a single surgeon. Anticancer Res 36(4): 1991-1998, 2016.

22 Gleason DF: Classification of prostatic carcinoma. Cancer Chemother Rep 50: 125-128, 1966.

23 Pierorazio PM, Guzzo TJ, Han M, Bivalacqua TJ, Epstein JI and Schaeffer EM: Long-Term Survival after Radical Prostatectomy for men with High Gleason Sum in the Pathological Specimen. Urology 76(3): 715-721, 2010.

24 Hanks GE, Buzydlowski J, Sause WT, Emami B, Rubin P, Parsons JA, Russell AH, Byhardt RW, Earle JD and Pilepich MV: Ten-year outcomes for pathologic node-positive patients treated in RTOG 75-06. Int J Radiat Oncol Biol Phys 40: 765$768,1998$.

25 Huang Y, Isharwal S, Haese A, Chun FKH, Makarov DV, Feng Z, Han M, Humphreys E, Epstein JI, Partin AW and Veltri RW: Prediction of patient-specific risk and percentile cohort risk of pathological stage outcome using continuous PSA measurement, Clinical Stage and biopsy Gleason score. BJU international 107(10): 1562-1569, 2011.

26 Pound CR, Brawer MK and Partin AW: Evaluation and Treatment of Men with Biochemical Prostate-Specific Antigen Recurrence Following Definitive Therapy for Clinically Localized Prostate Cancer. Rev Urol 3(2): 72-84, 2001.

27 Oefelein MG, Smith N, Carter M, Dalton D and Schaeffer A: The incidence of prostate cancer progression with undetectable serum prostate specific antigen in a series of 394 radical prostatectomies. J Urol 154(6): 2128-2131, 1995.

28 Ciftci S, Yilmaz H, Ciftci E, Simsek E, Ustuner M and Yavuz $\mathrm{U}$ : Perineural invasion in prostate biopsy specimens is associated with increased bone metastasis in prostate cancer. Prostate 75(15): 1783-1789, 2015.

29 Cheng L, Jones TD, Lin H, Eble JN, Zeng G, Carr MD and Koch MO: Lymphovascular invasion is an independent prognostic factor in prostatic adenocarcinoma. J Urol 174(6): 2181-2185, 2005.

30 Wright JL, Dalkin BL, True LD, Ellis WJ, Stanford JL and Lange PH: Positive surgical margins at radical prostatectomy predict prostate cancer specific mortality. J Urol 183(6): 2213-2218, 2010.

Received May 23, 2017

Revised June 21, 2017

Accepted June 23, 2017 